\title{
"We Get to Decide": The Role of Collective Engagement in Counteracting Feelings of Confinement and Lack of Autonomy in Residential Care
}

\author{
Ilka H. Gleibs, Stefanie J. Sonnenberg, Catherine Haslam
}

Maintenance of well-being is recognized as important for well-being in residential care, but the particular contribution that social groups and group activities make in this context is rarely considered. To understand how we can foster well-being in care, this study explores $(a)$ older adults' general experiences of life in long-term residential care and $(b)$ their particular experiences of participation in this group intervention. Ten semi-structured interviews were conducted with long-term care home residents and interview transcripts were analyzed thematically. Thematic analysis revealed two overriding themes that illustrated participants' general experiences of life in care. The first theme, "care home as home," suggests that adjustment and positive social relations with carers play a role in enhancing well-being. The second theme, "being stuck," describes a general sense of confinement and a lack of control associated with living in long-term care. The significance of collective engagement became evident in relation to this second theme. Specifically, participants' involvement in the group activity considered here was experienced as making a positive contribution to building social relations with other residents and, in doing so, as reducing residents' sense of confinement and lack of control. Engagement in the group intervention and the resulting positive social relationships were thus experienced as a means of counteracting participants' sense of being stuck. Overall, the findings point to the importance of group activities in fostering older adults' autonomy and control — and thus well-being — in care.

Increased life expectancy, changes in family structure, and families living apart are contributing factors to the growing need for residential care support (Ice, 2002; Office for National Statistics [ONS], 2011). Moving into residential care is often perceived as a negative life transition: it frequently follows bereavement and illness (Lee, Woo, \& Mackenzie, 2002) and often results in reduced autonomy (Anderson-Hanley, Meshberg, \& Marsh, 2003; Iwasiw, Goldenberg, Bol, \& MacMaster, 2003). It is therefore unsurprising that older adults' well-being in residential care can be compromised, and that symptoms of depression are frequently reported (Godlove-Mozley et al., 2000; Ice, 2002). Attempts to empower residents through control-enhancing (e.g., Langer \& Rodin, 1976; Slivinske \& Fitch, 1987), as well as social group (e.g., Haslam et al., in press-a; Knight, Haslam, \& Haslam, 2010), interventions generally attest to their positive effects on well-being and mental health. However, in these studies the voices of residents themselves are often absentdespite their importance for understanding which types of intervention are meaningful and, hence, worth investment. In this article we address this gap in the literature and explore older adults' 
subjective experiences of living in long-term care within the context of a group intervention, paying specific attention to the role of autonomy in this context.

\section{Empowering residents in care}

Control-enhancing interventions, aimed at increasing residents' sense of autonomy, were among the first to be implemented systematically in care and to produce positive effects on mental and physical health (e.g., Anderson-Hanley et al., 2003; Langer \& Rodin, 1976; Rodin \& Langer, 1977; Slivinske \& Fitch, 1987). Langer and Rodin's (1976) experimental study, which aimed to increase residents' sense of responsibility, provides a clear illustration of these effects. In the treatment condition, residents were briefed on the importance of taking responsibility (e.g., by looking after a plant) and were encouraged to make decisions about their daily lives. Residents in the control condition were advised that all aspects of their care were entirely the responsibility of care home staff. The findings showed that residents who received the treatment were more active, alert, and happy than those in the control group (Langer \& Rodin, 1976). Most strikingly, the intervention's positive effects were maintained 18 months later (Rodin \& Langer, 1977). Nurses' ratings, health, and mortality indicators continued to be more positive for the treatment group, suggesting that increased responsibility and control had sustained health benefits.

Such intervention, while beneficial, tends to be delivered one on one (although see Mercer \& Kane, 1979, for an exception) and, with growing evidence of the health benefits associated with group empowerment (e.g., see Haslam et al., in press-a; Knight et al., 2010), a pertinent question is whether perceptions of control can be further enhanced when people are engaged in a social group context. One aim of the present study was to explore this potential.

\section{Empowerment and social group membership}

A recent study involving residents in care provides a powerful demonstration of the influence that social groups can have on perceived control and well-being (Knight et al., 2010). Here, residents were empowered to make decisions about the decoration of the communal spaces of their newly refurbished home. Those on an experimental floor were engaged as a group to make decisions about the plants, pictures, and layout of communal areas (e.g., layout, choices of plants, pictures). Residents on the control floor had staff and managers make these decisions. When followed up 1 and 4 months later, residents in the experimental condition reported not only increased identification with staff and other residents but also improved well-being. Conversely, residents in the control group displayed patterns of general decline. 
This work was extended by Haslam et al. (in press-a) who examined how collective empowerment of this form, in the more common context of home redecoration, influenced cognitive integrity. In this study, residents were assigned to one of three conditions: (1) an empowered intervention condition, in which residents chose the plants, pictures, and wall color of their lounge, (2) a comparison condition where staff made these decisions on behalf of residents, and (3) a control condition, where there was no change. Residents in the empowered condition showed significant overall improvement relative to those in other conditions, both in cognitive function and social engagement.

These studies show that group-based interventions aimed at facilitating residents' choices can increase people's sense of ownership and engagement as well as contribute to a sense of belonging - all of which are key to maintaining well-being (Brink, 1993; Haslam et al., 2008; Hauge \& Heggen, 2007; Jetten \& Pachana, 2011; Knight et al., 2010; Ozaki, Uchiyama, Tagaya, Ohida, \& Ogihara, 2007). Thus, combining these elements of empowerment, engagement, and social interaction may provide a recipe for optimizing well-being outcomes among care home residents.

\section{Social identity, health, and group intervention}

The relationship between empowerment and social belonging - and more precisely a shared sense of social identification - is well established in the social and organizational psychology literature (Haslam, 2004; Haslam et al., 2009). Drawing on social identity and self-categorization theories (Tajfel \& Turner, 1979; Turner, Hogg, Oakes, Reicher, \& Wetherell, 1987), this literature shows that positive interaction and engagement with others can provide the basis for developing a shared sense of identity — or "we-ness" — which, in turn, has positive effects on various dimensions of social functioning and well-being.

The approach has recently been extended to understand why people who are more socially connected have better health (e.g., see Berkman \& Syme, 1979; Boden-Albala et al., 2005; EversonRose \& Lewis, 2005; House, Landis, \& Umberson, 1988). Here it is argued that membership in self-defining social groups (e.g., those defined by family, work, community, sport, religion) is key to gaining health benefits (Haslam et al., 2008; Jetten, Haslam, Iyer, \& Haslam, 2009; Jetten \& Pachana, 2011). However, this is dependent on the degree to which these groups are psychologically integrated into one's self-definition and other group members are therefore embraced as "we" or "us." It is only when group membership becomes an integral part of the self that groups provide a vital source of health-enhancing emotional and social support to counteract the effects of stress and adversity imposed by trauma and illness. In effect, such groups offer a psychological resource to contend with life's challenges (Haslam et al., 2008; Iyer, Jetten, 
Tsivrikos, Postmes, \& Haslam, 2009; Jetten, Haslam, Pugliese, Tonks, \& Haslam, 2010; Jones \& Jetten, 2011).

\section{The ladies' and gentlemen's clubs}

Numerous social intervention studies have demonstrated the positive effects that social identification has on the well-being of seniors in care (Gleibs, Haslam, Haslam, \& Jones, 2011a; Gleibs et al., 2011b; Haslam, Jetten, Haslam, \& Knight, 2011; Haslam et al., 2010, in press-a; Knight et al., 2010). For instance, in Gleibs et al.'s (2011b) study the benefits of a specific genderbased intervention, involving the formation of ladies' and gentlemen's clubs, was examined.

This study was the result of resident-driven intervention, initiated by a group of men in care who developed a gentlemen's club. The club allowed its members to engage in activities of their own choosing (e.g., outings to museums, lunches, pub visits, excursions) in addition to providing them with an opportunity for social interaction related to gender-specific issues (e.g., past work experiences and shared interests). Informal observations by the home's care staff, and conversations with the club's participants, indicated that these group activities were beneficial for the men's wellbeing, especially in creating relationships with others. As a consequence, women residents also expressed a wish for similar opportunities, thus giving rise to a ladies' club.

To examine the effects of this particular activity, new ladies' and gentlemen's clubs were created in several care homes managed by a care provider in the southwest of England. Participants in these clubs were involved in decisions about the group's activities, which included outings, flower arranging (women only), movie afternoons, and lunch-time outings. Groups met on a fortnightly basis and were facilitated by a staff member of the same gender as the group. All facilitators were experienced care staff who had introductory training in delivery of the activity and could turn to the Education and Training Coordinator of Cornwall Care for support.

The initial effects of these clubs (5 gentlemen's and 4 ladies' clubs) are reported in Gleibs et al. (2011b). After 12 weeks there was evidence of maintained well-being and identification with other residents for women, but a significant and marked improvement for men. Only among men was there a significant reduction in symptoms of depression and anxiety and an increased sense of identification with others in care. The group intervention, therefore, had particularly strong benefits for men, who are a minority in care, fostering an increased sense of belonging.

However, like other studies in this area (e.g., Haslam et al., 2010; Knight et al., 2010), Gleibs et al.'s (2011b) quantitative analysis offered little in terms of understanding residents' subjective experiences of this group intervention. Yet, such an understanding is important given that experiences of autonomy and well-being are often highly subjective. Moreover, in order to develop 
optimal social interventions, it seems essential to take the subjective views of older adults living in care into account. Here we aim to address this issue by adopting a qualitative approach.

\section{The current study}

The present study formed part of a larger, mixed-method research program evaluating the impact of the previously mentioned gender-based social intervention on adjustment to life in residential care. The research program drew on the social identity perspective, with an analytic emphasis on participant's autonomy and well-being. While Gleibs et al.'s (2011b) quantitative study assessed the intervention's impact on a range of cognitive and social outcome measures, the current study aimed to explore the experiential phenomenon of (a) living in residential care and (b) participation in the gentlemen's and ladies' clubs.

As already indicated, a qualitative stance was adopted to examine the following (initial) research questions: (1) How do older adults experience life in long-term residential care? (2) How do residents experience participation in the clubs? Semi-structured interviews were conducted with residents who had taken part in the intervention, and interview transcripts were analysed using thematic analysis (Braun \& Clarke, 2006; see further on for details). Importantly, though, in the process of conducting this study, the clubs were unexpectedly discontinued due to funding cuts. Because all interviews were conducted after the intervention was discontinued, the residents' loss of these clubs became part of their experience. Given this, the second research question was adjusted accordingly to examine this loss.

\section{Method}

\section{Participants}

Residents in five southwest England care homes were contacted via their respective home managers and invited to take part in this study. Care managers assisted in identifying participants who met the following inclusion criteria: ability to provide independent informed consent, had involvement in the gender clubs (i.e., the social intervention), and had sufficient physical and mental stamina for participation in an interview. Ten participants ( 5 men, 5 women, all White and British) agreed to take part and were recruited from five different residential facilities that were all run by the same provider. All participants had been members of the ladies' and gentlemen's clubs for severalmonths before they were discontinued due to funding cuts. Participants had spent between 2 and 9 years living in residential care and their ages ranged between 76 and 99 years. 


\section{Procedure}

As already mentioned, the social intervention under consideration here-the gentlemen's and ladies' clubs - was initiated by residents. Participation in the clubs was voluntary and informal, and residents who joined the clubs chose the activities in which their respective group took part.

However, as already stated, for staffing and financial reasons the clubs were discontinued. The data collection took place 2-4 months after the clubs had ceased. Interviews were between 20 and 40 minutes in length, were audio-recorded, transcribed verbatim, and were fully anonymized. In the following result section pseudonyms are used.

\section{Interview Schedule and Data Collection}

Following ethical approval (provided by the Psychology Ethics Committee at the researchers' university), data were collected by members of the research team. A semi-structured interview schedule was used, designed to elicit accounts of $(a)$ participants' experiences living in care and $(b)$ experiences of participation in the ladies' and gentlemen's clubs. Open-ended questions were designed to elicit spontaneous accounts and reflections, while more specific probes were used to explore in greater depth participants' original explanations. The interview schedule was refined in response to a pilot interview that served to gauge the appropriateness of our questions and prompts. Participants were interviewed individually in their own rooms, with one exception where three participants' requested a collective interview in the presence of two members of care staff.

\section{Analytic Strategy}

Data were analyzed using thematic analysis (Braun \& Clarke, 2006) — a method for coding, analyzing, and reporting themes within qualitative data. Thematic analysis is compatible with an inductive, data-driven approach while, at the same time, allowing for a more deductive integration of prior theory and research (Allen, Bromley, Kuyken, \& Sonnenberg, 2009). Because this analytic approach is appropriate for use in multi-method contexts, it allowed for the present study's embeddedness in a larger research program that included a quantitative component.

A detailed description of the analytic process followed for this study can be found in Allen et al. (2009). In brief, the analysis aimed to establish a hierarchy of overarching or main (analytic) themes and subthemes, with the latter remaining as close as possible to the verbatim transcripts. In line with Braun and Clarke (2006), initial coding involved the identification of expressions, events, and actions that depicted ideas pertinent to the research questions. The appropriateness of initial codes was checked by each member of the research team (i.e., early coding was carried out individually and emergent codes were subsequently discussed collectively among the researchers to ensure their reliability). Initial codes were then further differentiated (i.e., so as to reflect different 
nuances of meaning) or grouped together (i.e., to reflect shared meanings), thus gradually allowing for the development of an analytic hierarchy of explanatory themes. The analytic process was iterative (i.e., involving constant comparison between transcripts, excerpts, and code) to ensure that the resultant thematic structure remained grounded in the data. Again, the integrity and coherence of the emerging thematic hierarchy was checked regularly throughout analysis by every member of the research team (both individually and collectively).

\section{Findings}

As already stated, the study's objectives were twofold: (1) it aimed to explore older adults' experiences of living in long-term residential care and, in that context, (2) their experiences of participating in a specific group activity, namely the gentlemen's and ladies' clubs (including the loss of these clubs due to financial constraints). Thematic analysis of the interviews led to the identification of several themes. Depending on their analytic scope and explanatory strength, themes were categorized as either "main themes" or as "subthemes," with the former being analytically inclusive of the latter. In this section the two main themes identified in the analysis are presented as subheadings (see Themes 1 and 2 further on) while their corresponding subthemes are presented in italic.

In the following sections, we present each main theme by providing a broad description, followed by an elaboration of each theme in terms of its constituent subtheme(s), including evidence from respondents' verbal accounts. It is important to note, however, that while the following presentation of (sub)themes is unavoidably sequential, this masks the fact that there was a certain degree of overlap between themes. Both Themes 1 and 2 reflect qualitative aspects associated with participants' general experiences of life in care (in line with research objective 1). The relevance of the group activity under consideration here for these experiences (in line with research objective 2) is elaborated under Theme 2.

\section{Theme 1: The Care Home as "Home"}

Residential care institutions seek to provide services that meet their residents' daily needs. Despite these efforts, these settings are frequently portrayed negatively - a fact of which residents themselves are often aware ("I read in the paper, there was a story about bad care homes, "Stan, 89). ${ }^{1}$ Whether interviewees eventually came to refer to their care home as "home" appeared to be contingent on various factors: personal, social, as well as structural. 
Moving into residential care is frequently associated with loss, failing abilities, and disengagement from the world (Moss \& Moss, 2007). As a consequence, the notion of adjustment featured in interviewees' accounts of their experience.

(1) I quite like my own reading and television ... really. There isn't a lot-well you could go down to the day care center. Everyone seems so much older than me anyway. And I suppose at the moment, I need a bit of time to adjust to being in here. (Pamela, 76)

Here a move into residential care is associated with leaving one's previous life behind, thus requiring a period of acclimatization. Interestingly, the previous excerpt seems to reflect some process of adjustment "to being in here" — rather than to being "here"- which suggests, in this instance, that the care home is not (yet) experienced as "home." Moreover, "being $\underline{\text { in }}$ here" conveys a sense of the respondent's entrapment and, as such, foreshadows the confinement theme that will be discussed shortly. However, participants' experiences of living in residential care were neither necessarily, nor unanimously, negative ("I got no grumble with the place at all. . . I think this is probably one of the best [care homes], "Stan, 89). Some respondents seemed to experience the care home not only as their home but also staff as family, as is illustrated by an excerpt from Reg's interview:

But this is like you living [in] your home. . . And carers who have been away on maternity leave, they bring their nippers in to see us. That's what I mean, and as Angelina [care home manager] said, we are like one big family. (Reg, 79)

There are two interesting analytic points that can be raised on the basis of this quote. First, it suggests that the extent to which residents accept the care home as "home" or family seems to be a function of social relations - particularly the relations between staff and residents. In this instance, for example, the resident's inclusion in a staff member's personal life ("they bring their nippers in to see us") contributes to a sense of home and family. Second, the extract illustrates that respondents' positive experiences with regard to living in residential care go hand in hand with the personalization of staff - that is, members of staff are regarded as individuals or persons. Whenever interviewees appeared to embrace the notion of the care home as "home" in the context of recollecting positive experiences (i.e., feeling respected, having positive rapport with staff), staff members were personalized and referred to by name ("Alison who is up in housekeeping”; "That um, a chap called, now what's his name, Ray"; "We got a good lady . . Tina she was called"; "Jo is leaving, and I have got a bouquet to give her before she goes"). Conversely, negative experiences were associated with a tendency to draw a line between "us" (residents) and "them" (staff), resulting in the depersonalization of individual staff members. For example, depersonalized language was used when residents spoke about their experience of a lack of communication with staff ("They haven't said a word to us"), residents' lack of mobility ("Yes, they had to move us 
down"), or a shortage in staff ("They seem to be short of staff"). This particular use of language was evident in all transcripts and juxtaposes respondents' experiences of the care facility as "home" or "family" with their experiences of it as an institution clearly divided between residents and staff (with their respective, competing needs). This analysis speaks to our first research objective and suggests that initial adjustment as well as ongoing social relations, especially with care home staff, play a crucial role in shaping older adults' experiences of living in residential care.

The significance of social relations, albeit with other residents rather than with staff, also formed an important aspect (i.e., subtheme) of Theme 2. As will become evident shortly, here the gentlemen's and ladies' clubs played a crucial role in fostering positive relationships among residents. However, before examining the relevance of these gender clubs for social relations and well-being among residents, one recurrent theme in respondents' descriptions of their general experiences of life in care needs to be examined, namely their sense of "being stuck."

\section{Theme 2: "Being Stuck"}

Although there was undoubtedly variation in participants' accounts of their experienceswith some residents reporting positive aspects associated with living in care (see previously) - the one experience that interviewees seemed to share was a sense of "being stuck."

We are stuck in here day after day. . . You sit here and you just wait to die. (Phyllis, 92)

"Being stuck" was an in vivo theme (i.e., interviewees frequently used this particular expression, or close variants of it) in the majority of transcripts. This participant's account of being "stuck in here" and "just wait[ing] to die" paints a powerful image of a resident's entrapment, (enforced) passivity, and sense of resignation. The idea of "being stuck," in turn, encompassed several subthemes: in many cases and as already suggested earlier, it expressed quite literally a sense of physical confinement in a particular space/place, characterized by a lack of mobility and activity. However, this theme also portrayed confinement in a psychological sense in so far as it related to (a lack of) control or autonomy. Finally, as will be shown further on, participants' accounts of "being stuck" were often closely linked with, and counteracted by, their experiences of the social intervention under consideration here as part of our second research objective. In this way, participation in the gentlemen's and ladies' clubs seemed to provide a means of becoming "unstuck" through creating the opportunity for developing social relations among residents. Following, each of these aspects or subthemes are elaborated in turn.

Evidence for participants' sense of physical confinement emerged in many descriptions of a general lack of mobility or physical activity.

'Cause we sit for hours and don't speak to no-one. 'Cause you-what do you say? You said it in the morning. Then this afternoon you had nothing to say. (Cathy, 90) 
Here the participant's lack of physical mobility or activity ("we sit for hours") and thus the monotony of daily life in care are directly linked to the absence of meaningful social interactions or communication with other residents ("you had nothing to say”). In other words, interviewees regarded their physical inactivity as having a direct impact on their well-being, leading to an increased feeling of social isolation (e.g., "I mean it's a care home, you know-I get left very much to my own devices, "' Stan, 89).

Analysis also suggested that for many interviewees a lack of mobility or physical activity and the resultant sense of confinement contributed to an increased feeling of dependency on staff. This, in turn, was associated with a loss of control - a subtheme that will be discussed shortly. The important issue to note here is that, for some participants, their perceived confinement was rather literal and was caused by structural changes in the care home environment. As one interviewee put it: We say it's like being in a dungeon down here. (Pamela, 76)

The "dungeon" in question here, in fact, was the lower ground floor in one particular care home to which more able residents were moved. This was done to allow residents with dementia to have ready access to physically open space with the understanding that more able residents could ask staff to help them up to the first floor via the stairs or elevator. Nevertheless, this had the unfortunate consequence of increasing the perceptions of confinement and reducing feelings of control among residents. As a consequence, the ensuing move was experienced as distressing by those residents who now lived in an environment (the "dungeon") that had originally been designed to protect adults with dementia. These structural changes had a noticeable impact on residents' well-being.

Oh I was much happier upstairs than down here. I don't like it down here, there is nowhere to walk. ... I think that people think we will be happy sitting doing nothing. But it doesn't appeal to me, I like exercise. (Phyllis, 92)

Here the lack of physical mobility or activity is not only related to a sense of confinementdue to the structural layout of the care home- - but it also taps into the stereotypical assumption that older adults lack interest in physical activity (Moss \& Moss, 2007).

As signposted previously, "being stuck” or confined was often countered by residents' positive recollections of participation in either the gentlemen's or ladies' clubs. In this way, the group activity provided an important, and at times essential, means of counteracting this sense of confinement. As one respondent put it:

I think it's [the gentlemen's club] essential. I mean when you're confined to a place like this. I looked forward to it greatly. ... Yes, we become a team, a team. (Ted, 88)

The gentlemen's and ladies' clubs were experienced as positive by all interviewees who had participated in this social intervention. As this quote suggests, they were seen as an essential 
antidote to a general lack of activity and social isolation. However, the previous excerpt also alludes to a perhaps more fundamental social psychological process, namely the clubs' abilities to foster social relations among residents and to create a sense of belonging to a group ("we become a team"). Engagement with the gender-based clubs allowed residents to forge friendships with one another (Interviewer: "Were you friends with Bill and Reg before . . ? Stan: "No, no it was through the men's club.") that seemed to continue even after the withdrawal of the social intervention for funding reasons. We shall return to this issue shortly.

As already suggested, the theme of "being stuck" not only described participants' sense of physical confinement (i.e., lack of mobility or activity) but also encompassed a sense of psychological entrapment that was expressed in terms of (a lack of) control or autonomy. In fact, lack of control is a common theme that has been identified in a number of studies with older adults in residential care (e.g., Joseph Rowntree Foundation, 2009; Langer \& Rodin, 1976), where findings suggest that living in care often fails to provide residents with a sense of autonomy in daily life (e.g., control over everyday activities such as going for a walk, choosing food, or making decisions about how to structure one's day). In our participants' accounts of their experiences, issues of control frequently manifested as a sense of (physical) dependency on others, particularly on staff.

But you know somebody has got to take you every time you want to go anywhere. You know, whether you want to, somebody has got to take you up there [to the ground floor]. (Pamela, 76)

In this example, the participant's dependence on staff — and the resultant lack of autonomyis a direct function of the structural features of the care facility (e.g., the previous excerpt, "We say it's like being in a dungeon down here”), which, in turn, severely limit residents' physical mobility ("somebody has to take you every time you want to go anywhere"). Dependency, physical mobility, and lack of control or autonomy therefore appear to be intimately linked. In many participants' accounts, this lack of autonomy was contrasted by assertions of independence and the need to be recognized as autonomous individuals (e.g., "I don't just let people order me about-'do this, do that, do the other, 'you know, " Stan, 89; “I mean, we have a mind of our own, " Fred, 84). In other words, despite the physical constraints older adults living in care might face, residents stressed their individual agency, requesting to be recognized as independent decision makers.

Notably the subtheme of control - especially in terms of independent decision makingfrequently emerged within respondents' descriptions of participating in the gentlemen's and ladies' clubs. The social intervention appeared to play a significant role in fostering a sense of autonomy and control among participants by allowing them to make their own decisions, even if on a small scale (e.g., choosing food in a restaurant: "well, you could have what you liked, you see, there was a 
menu and you could have what you liked," Phyllis, 92). Also, participation in the social intervention facilitated decision making in so far as it offered respondents an actual choice with regard to the type of activity in which they engaged.

The young chap [carer] who organizes things [the club's social activities such as museum visit, trip to seaside] . . . he'll come and will ask us [for preferences regarding activities]. And then we can have a good time. We get to decide. (Stan, 89)

The provision of choice or control ("we get to decide") was repeatedly stressed as a significant feature of the social clubs and was clearly linked to an enhanced sense of well-being ("we can have a good time"). Conversely, the withdrawal of the social intervention was associated with a loss of autonomy.

I wish they would get the outings [the gender-based social clubs] up and running again, cause I mean, we can't do anything about it, it's not up to us, is it? (Rose, 77)

Here the withdrawal of the social clubs is not only regarded as a loss of activity, but is also associated with a sense of powerlessness ("we can't do anything about it, it's not up to us").

We have already alluded to the social intervention's function in terms of fostering social relations among residents and creating a sense of group belonging. The significance of the gentlemen's and ladies' clubs in developing social relations - in particular in terms of becoming “ $a$ team" (see the previous excerpt, "Yes, we become a team, a team")—is perhaps best illustrated by another extract from Phyllis's account. When asked to describe what the ladies' club involved, Phyllis stated:

We used to go to [place name]. And we use to have our lunch there. And then we could always walk around the shops, you see. And it was very good for us 'cause we could buy things there if we wanted to. (Phyllis, 92)

Again, the importance of having a degree of control is evident here ("we could buy things there if we wanted to"). More importantly, the quote hints at a sense of freedom in terms of mobility or activity ("we could always walk around the shops"). This seems rather intriguing in this particular context because this participant was, in fact, a wheelchair user who also had difficulties using her hands (i.e., she required assistance with pushing the chair). Objectively, her mobility with regard to "walk[ing] around the shops" would therefore have been severely compromised. Yet, subjectively, the club's outings seemed to afford a tangible sense of physical freedom, as the continuation of Phyllis's account demonstrates.

Well, Helen used to take us-then one of the carers used to drive the van. ... And . . they took me out in a wheelchair. And Sandra, who is blind, next door-Sandra [age 93] used to push me, and I used to tell her where to go. And we used to enjoy that. (Phyllis, 92) 
Here a powerful image is created: a blind woman pushing another woman's wheelchair, with directions being issued by the latter. It is the combination of both women's abilities - in other words, "becom [ing] a team"- that enables them to overcome their individual physical limitations. This, in turn, allows them to move more freely and adds to a greater sense of well-being ("we used to enjoy that"). In this way, the social relations fostered among residents not only counteract individuals' social isolation and lack of control but also transcend their physical confinement. Here, the social relations forged by participation in the club are quite literally enabling residents to become "unstuck." This, then, is diametrically opposed to "sit[ting] here, just wait[ing] to die."

In sum, this analysis suggests that a sense of physical as well as psychological confinement plays a crucial part in shaping residents' experiences. Participation in the social intervention under consideration here seemed to reduce this sense of confinement, thus contributing to an increased sense of well-being — at least temporarily_via enhanced control and social engagement.

\section{Discussion and conclusion}

This interview study explored older adults' subjective experiences of living in long-term residential care and, in particular, their experiences of participation in a social group intervention (i.e., the gentlemen's and ladies' clubs). Two overarching themes emerged from the interviews. First, findings suggested that quality of life in care was closely related to the perception of "the care home as home." Second, living in residential care was frequently associated with "being stuck." Both of these themes related to older adults' well-being. The study's findings highlight the importance of involvement in group activities, especially for counteracting a sense of diminished well-being as a function of a loss of control and autonomy.

The first main theme - the "care home as home" - consisted of two (interrelated) subthemes, namely adjustment and social relations with staff. Adjustment to life in care seemed to be achieved primarily through positive social relations with care staff, highlighting the importance of interpersonal relationships between care staff and residents. This finding is in line with previous research emphasizing the maintenance of social relationships in general as an important aspect of older adults' quality of life (Bowling \& Gabriel, 2007). While adjustment to life in care can be perceived as challenging (Iwasiw et al., 2003), it can also be facilitated through meaningful staffresident relationships. Despite the existence of research addressing the relationship between care in general and quality of life (Hannan, Norman, \& Redfern, 2001), there is surprisingly little work on the specific links between life quality and residents' personal relationships with staff. Future research in this domain might therefore prove fruitful.

The second main theme emerging from the analysis— "being stuck" — was associated with negative experiences of living in care and, in particular, was characterized by residents' sense of 
physical and psychological confinement. Notably, participants' accounts conveyed a general sense of a lack of control and decision-making power. This, then, raises questions about the impact such feelings might have on residents' overall sense of integrity and their self-perceptions as independent, active, or resourceful persons (Langer \& Rodin, 1976). Importantly, the current findings also suggest that the social intervention under consideration allowed participants to regain a sense of control and to reinstate their decision-making power. The group intervention allowed participants to develop social relations with other residents (and staff) — another subtheme identified here. Residents described the development of friendships and social support as a function of their participation in the social clubs. Overall, the gender-based intervention appeared to be an important vehicle for creating positive relationships with others, enabling residents to use their combined strength and abilities to compensate for individual limitations. Thus, collective engagement seemed central to enhancing residents' quality of life.

As already stated, the group intervention was unexpectedly discontinued during the course of this research - and residents evidently missed the clubs. Their discontinuation and the absence of other meaningful opportunities for social engagement echo other findings (Hancock, Woods, Challis, \& Orrell, 2006; Harmer \& Orrell, 2008). Due to staffing and funding constraints, enabling social activities in care is not always considered a priority. Under such constraints, social activities are often the first in line to be cut, leading to an (over)emphasis on physical care over psychosocial care. There can be an implicit assumption that ageing is naturally accompanied by a reduced need for general activity and social contact (Cumming, Dean, Newell, \& McCaffrey, 1960; Gilleard \& Higgs, 2000; Kitwood, 1997) — an overemphasis on physical care could thus be a reflection of broader stereotypes surrounding old age (Kite, Stockdale, Whitley, \& Johnson, 2005). Yet, the current analysis suggests that the provision of good care goes beyond simply meeting physical needs. Well-being in care also requires residents' involvement in meaningful social activities that foster a sense of belonging and autonomy.

In particular, the group intervention examined in this study seemed to meet some fundamental psychological needs. Residents felt enabled by participating in this intervention, perceived themselves to have greater choice and autonomy, and expressed a greater sense of belonging. Kitwood (1997) identifies all of these factors as critical in delivering person-centered care. The present findings are therefore consistent with previous claims that group-based activities are an important vehicle for delivering meaningful and engaging opportunities for older adultsparticularly with regard to maintaining well-being and counteracting negative experiences (Gleibs et al., 2011b).

In this context, it might therefore be argued that social activities that emphasize creating a meaningful and purposeful group or community are especially beneficial. In fact, there is emerging 
evidence, drawn from a range of group activities, in support of this claim. Studies on group interventions focusing on such diverse activities as, for example, reminiscence (Haslam et al., 2010; Haslam, Haslam, Ysseldyk, McCloskey, Pfisterer, \& Brown, in press-b), decision making (Haslam, Haslam, Knight et al., 2014; Knight et al., 2010), and water intake (Gleibs et al., 2011a) have demonstrated an enhanced a sense of belongingness, compared to individually focused interventions. In addition, group activities have been shown to provide a better basis for maintaining psychological well-being and engagement with others in care.

However, our capacity to draw definitive conclusions on the basis of these findings is clearly limited. In particular the study's sample size was small and this, in turn, placed some constraints on the analysis and findings. Moreover, although the main findings of this study are consistent with previous theorizing and empirical work, further research is needed to show explicitly how wellbeing would have been influenced by the continuation of the social activity. Another concern might be that our sample comprised exclusively White British participants, and we did not request information about sexual orientation. Thus, while we argue that greater social engagement will protect well-being, we assume this on the basis of a relatively homogenous group of participants with no apparent cultural diversity.

In the present case, the absence of diversity within the sample is largely a reflection of resource constraints and geographic location. Relatedly, it also reflects the logistical challenges involved in conducting studies of this form. Importantly, though, we believe that the present study provides evidence that can be used as a basis both for conducting further research to test the ideas that we have outlined and providing some direction in addressing the question of what constitutes meaningful activity in residential care (Harmer \& Orrell, 2008), highlighting the importance of group activities for well-being (e.g., Forsman, Schierenbeck, \& Wahlbeck, 2011).

Future research might consider easy-to-implement social group interventions that involve residents, meaningfully and collectively, in decisions that have an impact on their lives. This could include involvement in meal planning and preparation, group outings, and gardening (e.g., Rodin \& Langer, 1977, 1996). These activities could be organized and run by residents themselves or their family members. Such involvement in collective decisions about the social environment would seem to be a rather simple way of making residents feel "at home" and thereby enhancing their psychological functioning (see Haslam, Haslam, Knight et al., 2014).

Our findings correspond to the growing social identity literature, which argues that meaningful social groups (and their underlying identities) are not only central to life experience but also crucial for health and well-being (see Haslam, Jetten, Postmes, \& Haslam, 2009; Jetten, Haslam, \& Haslam, 2011). In the current context, the creation of the social clubs enabled residents to counteract experiences of marginalization and loss of control by means of facilitating a sense of 
social identity (i.e., identification with others). Thus, the gender-based groups were perceived as a source of social support, and participation in them provided both a sense of control and a means of becoming "unstuck."

Older people in residential care often experience limited control over their own decisions and life situation. There is also a power imbalance between those who provide care and support and those who receive it. Relatively low-cost group interventions, such the clubs examined here, can provide residents with a sense of autonomy and belonging as well as social support. Maintenance of individual autonomy and social embeddedness seems crucial for well-being and thus for the delivery of good care. Good practice should therefore enable voice, choice, control, and social belonging (e.g., Joseph Rowntree Foundation, 2009). Resident-oriented social interventions of the form we propose here can promote each of these aspects of practice and do so in a way that optimizes health and well-being.

\section{Acknowledgements}

The authors thank Helen Connolly and Cornwall Care for their help with recruiting participants, and Jade McNeill for help in data collection and initial analysis.

\section{Funding}

Work on this article was supported by a grant from the Economic and Social Research Council (RES-062-23-0135) awarded to the third author and a British Academy Small Grant (SG-52142) awarded to all three authors. The funding bodies were not involved in the study design; the collection, analysis, and interpretation of data; nor in writing the report and submission of this article for publication.

Note

1. This negative cultural view was also in evidence in a recent BBC Panorama portrayal of systematic abuse in care home settings, which was followed by the collapse of one of the UK's most prominent care home groups (see http://www.bbc.co.uk/programmes/b011pwt6; http://www.bbc.co.uk/news/business-14102750). 


\section{References}

Allen, M., Bromley, A., Kuyken, W., \& Sonnenberg, S. J. (2009). Participants' experiences of mindfulness-based cognitive therapy: "It changed me in just about every way possible." Behavioural and Cognitive Psychotherapy, 37, 413-430.

Anderson-Hanley, C., Meshberg, S. R., \& Marsh, M. A. (2003). The effects of a control-enhancing intervention for nursing home residents: Cognition and locus of control as moderators. Palliative and Supportive Care, 1, 111-120.

Berkman, L. F., \& Syme, S. L. (1979). Social networks, host resistance, and mortality: A nine-year follow-up study of Alameda County residents. American Journal of Epidemiology, 109, 186204.

Boden-Albala, B., Litwak, E., Elkind, M. S. V., Rundek, T., \& Sacco, R. L. (2005). Social isolation and outcomes post stroke. Neurology, 64(11), 1888-1892.

Bowling, A., \& Gabriel, Z. (2007). Lay theories of quality of life in older age. Ageing and Society, $27,827-848$.

Braun, V., \& Clarke, V. (2006). Using thematic analysis in psychology. Qualitative Research in Psychology, 3, 77-101.

Brink, S. (1993). Elderly empowerment: New rights and research are enhancing nursing home life. US News World Report Journal, 114(16), 69-70.

Cumming, E., Dean, L. R., Newell, D. S., \& McCaffrey, I. (1960). Disengagement-A tentative theory of ageing. Sociometry, 23, 23-35.

Everson-Rose, S. A., \& Lewis, T. T. (2005). Psychosocial factors and cardiovascular diseases. Annual Review of Public Health, 26, 469-500.

Forsman, A. K., Schierenbeck, I., \&Wahlbeck, K. (2011). Psychosocial interventions for the prevention of depression in older adults: Systematic review and metaanalysis. Journal of Aging and Health, 23, 387-416.

Gilleard, C. J., \& Higgs, P. (2000). Cultures of ageing: Self, citizen, and the body. Upper Saddle River, NJ: Pearson Education.

Gleibs, I. H., Haslam, C., Haslam, S. A., \& Jones, J. (2011a). Water clubs in residential care: Is it the water or the club that enhances health and well-being? Psychology and Health, 26, 13611378.

Gleibs, I. H., Haslam, C., Jones, J., Haslam, S. A., McNeill, J., \& Connolly, H. (2011b). No country for old men? The role of a "gentlemen's club" in promoting social engagement and psychological well-being in residential care. Ageing and Mental Health, 15, 456-467. 
Godlove-Mozley, M. C., Challis, D., Bagley, S. C., Burns, H. A., Huxley, P., \& Cordingley, L. (2000). Psychiatric symptomatology elderly people admitted nursing residential homes. Aging and Mental Health, 4, 136-141.

Hancock, G. A., Woods, B., Challis, D., \& Orrell, M. (2006). The needs of older people with dementia in residential care. International Journal of Geriatric Psychiatry, 21, 43-49.

Hannan, S., Norman, I. J., \& Redfern, S. J. (2001). Care work and quality of care for older people: A review of the research literature. Review in Clinical Gerontology, 11, 189-203.

Harmer, B. J., \& Orrell, M. (2008). What is a meaningful activity for people with dementia living in care homes? A comparison of the views of older people with dementia, staff and family career. Ageing and Mental Health, 12, 548-558.

Haslam, C., Haslam, S. A., Jetten, J., Hayward, S., Bevis, A., \& Tonks, J. (2010). The social treatment: The benefit of group interventions in residential care. Psychology and Aging, 25, $157-167$.

Haslam, C., Haslam, S. A., Knight, C., Gleibs, I. H., Ysseldyk, R., \& McCloskey, L.-G. (2014). We can work it out: Group decision-making builds social identity and enhances cognitive performance in elderly care residents. British Journal of Psychology, 105(1), 17-34.

Haslam, C., Haslam, S. A., McCloskey, L. G., Ysseldyk, R., Pfisterer, K., \& Brown, S. (2014). Collective cognition in aging: Social identification moderates cognitive health and well-being following story-and song-based reminiscence. Aging and Mental Health. Advance online publication.

Haslam, C., Holmes, A., Haslam, S. A., Iyer, A., Jetten, J., \&Williams, W. H. (2008). Maintaining group memberships: Social identity continuity predicts well-being after stroke. Neuropsychological Rehabilitation, 18, 671-691.

Haslam, C., Jetten, J., Haslam, S. A., \& Knight, C. (2011). The importance of remembering and deciding together: Enhancing the health and well-being of older adults in care. In J. Jetten, C. Haslam, \& S. A. Haslam (Eds.), The social cure: Identity, health, and wellbeing (pp. 297315). London: Psychology Press.

Haslam, S. A. (2004). Psychology in organizations: The social identity approach. London: Sage.

Haslam, S. A., Jetten, J., Postmes, T., \& Haslam, C. (2009). Social identity, health, and well-being: An emerging agenda for applied psychology. Applied Psychology: An International Review, 58, 1-23.

Hauge, S., \& Heggen, K. (2007). The nursing home: A field study of residents' daily life in the common living rooms. Journal of Clinical Nursing, 17, 460-465.

House, J. S., Landis, K. R., \& Umberson, D. (1988). Social relationships and health. Science, 241(4865), 540-545. 
Ice, G. H. (2002). Daily life in a nursing home: Has it changed in 25 years? Journal of Aging Studies, 16, 345-359.

Iwasiw, C., Goldenberg, D., Bol, N., \& MacMaster, E. (2003). Residents and family perspective: The first year in a long term facility. Journal of Gerontological Nursing, 29, 45-54.

Iyer, A., Jetten, J., Tsivrikos, D., Postmes, T., \& Haslam, S. A. (2009). The more (and the more compatible) the merrier: Multiple group memberships and identity compatibility as predictors of adjustment after life transitions. British Journal of Social Psychology, 48, 707-733.

Jetten, J., Haslam, C., \& Haslam, S. A. (2011). The social cure: Identity, health, and well-being. London: Psychology Press.

Jetten, J., Haslam, S. A., Iyer, A., \& Haslam, C. (2009). Turning to others in times of change: Shared identity and coping with stress. In S. Stürmer \& M. Snyder (Eds.), New directions in the study of helping: Group-level perspectives on motivations, consequences and interventions (pp. 139-156). Hoboken, NJ: Wiley-Blackwell.

Jetten, J., Haslam, C., Pugliese, C., Tonks, J., \& Haslam, S. A. (2010). Declining autobiographical memory and the loss of identity: Effects on well-being. Journal of Clinical and Experimental Neuropsychology, 32, 408-416.

Jetten, J., \& Pachana, N. A. (2011). Driving cessation among older adults: Coping with identity change and transition. In J. Jetten, C. Haslam, \& S. A. Haslam (Eds.), The social cure: Identity, health, and well-being (pp. 97-113). New York: Psychology Press.

Jones, J. M., \& Jetten, J. (2011). Recovering from strain and enduring pain: Multiple group memberships promote resilience in the face of physical challenges. Social Psychological and Personality Science, 2, 239-244.

Joseph Rowntree Foundation. (2009). Older people's vision for long-term care. Retrieved from http://www.jrf.org.uk/publications/older-people-vision-longterm-care

Kite, M. E., Stockdale, G. D., Whitley, B. E., JR., \& Johnson, B. T. (2005). Attitudes toward older and younger adults: An updated meta-analysis. Journal of Social Issues, 61, 241-266.

Kitwood, T. (1997). Dementia reconsidered: The person comes first. Buckingham, UK: Open University Press.

Knight, C., Haslam, S. A., \& Haslam, C. (2010). In home or at home? Evidence that collective decision making enhances older adults' social identification, wellbeing and use of communal space when moving into a new care facility. Ageing and Society, 30, 1393-1418.

Langer, E. J., \& Rodin, J. (1976). Long-term effects of a control-relevant intervention with the institutionalized aged. Journal of Personality and Social Psychology,35, 897-902.

Lee, D., Woo, J., \& Mackenzie, A. E. (2002). A review of older people's experiences with residential care placement. Journal of Advanced Nursing, 37, 19-27. 
Mercer, S., \& Kane, R. A. (1979). Helplessness and hopelessness among the institutionalized aged: An experiment. Health and Social Work, 4, 90-116.

Moss, S. Z., \& Moss, M. S. (2007). Being a man in long-term care. Journal of Ageing Studies, 22, 43-54.

Office for National Statistics (ONS). (2011). 2010-based period and cohort life expectancy tables. Retrieved from http://www.ons.gov.uk/ons/dcp171780_238828.pdf

Ozaki, A., Uchiyama, M., Tagaya, H., Ohida, T., \& Ogihara, R. (2007). The Japanese centenarian study: Autonomy was associated with health practices as well as physical status. Journal of the American Geriatrics Society, 55, 95-101.

Rodin, J., \& Langer, E. J. (1977). Long-term effects of a control-relevant intervention with the institutionalized aged. Journal of Personality and Social Psychology, 35(12), 897-902.

Rodin, J., \& Langer, E. J. (1996). Long-term effects of a control-relevant intervention with the institutionalized aged. In S. Fein \& S. Spencer (Eds.), Readings in social psychology (pp. 175-180). Boston, MA: Houghton Mifflin.

Slivinske, L. R., \& Fitch, V. L. (1987). The effect of control enhancing interventions on the wellbeing of elderly individuals living in retirement communities. The Gerontologist, 27, 176181.

Tajfel, H., \& Turner, J. C. (1979). An integrative theory of intergroup conflict. In W. G. Austin \& S. Worchel (Eds.), The social psychology of intergroup relations (pp. 33-47). Monterey, CA: Brooks/Cole.

Turner, J. C., Hogg, M. A., Oakes, P. J., Reicher, S. D., \&Wetherell, M. S. (1987). Rediscovering the social group: A self-categorization theory. Oxford: Blackwell.

Wanklyn, P. (1996). Caring for older people: Homes and housing for elderly people. British Medical Journal, 313, 218-221. 


\section{Appendix}

The purpose of the following interview schedule is to facilitate an exploration of group/identity dynamics in participants' accounts of their lives in longterm care. In this context, we specifically seek to elicit people's experiences with regard to their participation in the gentlemen's/ladies' clubs (where appropriate) as a recent example of group involvement.

\section{Interview strategy and schedule}

Our overall strategy for the interview, which also informs the structure of the interview schedule, is as follows:

(A) Contextualize the interview: Ensure that interviewees are provided with an overall introduction to the study and the information necessary to provide a context for the interview (e.g., "as you know we're here to talk a little bit about the gentlemen's/ladies' clubs-this is because we're very interested in people's social lives and what kind of things they get up to socially-but before we talk about the clubs, I wonder whether you could tell us a little bit about yourself first").

(B) Elicit narrative/life story: Focus is on the person's social life/relations and his or her involvement in different groups throughout his or her life (e.g., "can you tell us a little bit about your social life and the kinds of things you used to do socially").

(C) Focus on life in care and the gentlemen's/ladies' clubs: Elicit people's experience of life in care in general and of their participation in the clubs in particular. (e.g., "could we now talk a little bit about your life here and your experiences with the clubs").

(A) Standardized Introduction

- Explain purpose of the study (see earlier)

(B) Narrative/Life Story

Overall intro: "We're interested to hear about the kind of social life you have/have had throughout different stages in your live, the groups you've belonged to, your relationships with others, and so on ..."

- Can you tell me a little bit about your life in general and your social life in particular, in the past?

- Tell me about the sorts of things that you've done with other people in your life? What have you enjoyed doing with others in the past? 
- What sort of things have you done when you were not working/outside of work?

- Have you ever belonged to any clubs/groups/teams? If so, can you tell me a little more about these? (Prompt: have you been a member of a club, the church, social groups/neighbors, etc.).

(C) Focus on Life in Care and the Gentlemen's/Ladies' Clubs

- Overall intro: "So we have talked about your life and social life in the past, let's move on to talk about your life here." Could you tell me a bit about your current life? What's it like? How would you describe your experiences here?

- Tell me a bit about the things you have been involved with here (e.g., are you a member of any groups? What sorts of activities are you involved in?)

- Tell me about the things that you are doing/have done here. What are the things that are socially going on here?

- Can we talk a bit about your experience with the ladies'/gentlemen's clubs?

- Prompt: What did you like about the club? What did you not like about the club?

- What sorts of things did you do?

$\circ$ Prompt: Did this matter to you? Did it make a difference to your life here in the home?

- Did you talk about the group much?

- Prompt: What did you talk about? Are you still talking about the club?

- Can you tell me what your favorite activity was? What was it about this experience that you liked in particular? 